\title{
FULL-WAVEFORM INVERSION USING AN EFFICIENT PRECONDITIONING METHOD FOR THE GRADIENT VECTOR APPLIED FOR DIFFERENT SOURCE SIGNATURES
}

\author{
Peterson Nogueira Santos ${ }^{1}$ and Reynam C. Pestana ${ }^{2}$
}

\begin{abstract}
Full-waveform inversion (FWI) is a efficient method and it has been used successfully to invert subsurface parameters. It consists basically on the minimization of the difference between the predicted and observed data. However, its application using finite-difference schemes is limited to low frequency content and the increase of the range of higher frequency will demand a high computational cost of the wavefield propagation procedure and also the whole inversion scheme. To overcome this problem, we apply the rapid expansion method (REM) for numerical wavefield extrapolation inside the FWI workflow thus increasing the frequency content of the inversion process. Besides that, an efficient preconditioning method using source-receiver illumination (PSRI) for computing the gradient vector in order to increase resolution of the models and better convergence of the objective function has also been proposed. Beyond that, we compared the performance of the preconditioning method with relation to conventional gradient method for two types of source signature. To test the efficiency of our proposed FWl approach, we apply it using a frequency multiscale scheme for a synthetic data set with a complex velocity model. The inversion results show satisfactory inverted velocity models which can be used to produce depth imaging of high quality. Thus we demonstrate the effectiveness and applicability of our FWI scheme using REM combined with a multiscale approach.
\end{abstract}

Keywords: full-waveform inversion, preconditioning method, rapid expansion method.

RESUMO. Inversão de forma de onda completa (FWI) é um método eficiente e tem sido utilizado com sucesso para inverter parâmetros de subsuperfície. Consiste basicamente na minimização da diferença entre os dados previstos e observados. No entanto, sua aplicação usando esquemas de diferenças finitas é limitada ao conteúdo de baixa frequência e ao aumento da banda incluindo mais altas frequências que demanda um alto custo computacional devido ao procedimento de propagação do campo de onda e também em todo o esquema de inversão. Para superar este problema, aplicamos o método de expansão rápida (REM) para a extrapolação numérica do campo de onda dentro do fluxo de trabalho da FWI, aumentando assim o conteúdo de frequência do processo de inversão. Além disso, também foi proposto um método eficiente de pré-condicionamento usando a iluminação da fonte e do receptor para o vetor gradiente que tem como objetivo aumentar a resolução dos modelos e a convergência da função objetivo. Dessa forma, comparamos o método de pré-condicionamento ao método gradiente convencional para dois tipos de assinatura da fonte. Para testar a eficiência de nossa abordagem de FWI proposta, utilizamos um esquema multiescala na frequência para um conjunto de dados sintéticos com um modelo complexo de velocidade. Os resultados da inversão mostram modelos de velocidades invertidos satisfatórios que podem ser utilizados para produzir imagens de profundidade de alta qualidade. Assim, demonstramos a eficácia e aplicabilidade do nosso esquema FWI usando REM combinado com uma abordagem multiescala.

Palavras-chave: inversão completa da forma de onda, método de pré-condicionamento, método de expansão rápida.

\footnotetext{
1 Universidade Federal da Bahia (UFBA), Centro de Pesquisa em Geofísica e Geologia (CPGG), Rua Barão de Jeremoabo, 123, Campus Universitário da Federação, 40170-115 Salvador, BA, Brazil. Phone: +55(71) 99161-7615 - E-mail: nogueirapeterson@gmail.com

2Universidade Federal da Bahia (UFBA), Departamento de Geofísica da Terra e do Meio Ambiente, Instituto de Física/CPGG, Rua Barão de Jeremoabo, 123, Campus Universitário da Federação, 40170-115 Salvador, BA, Brazil. Phone: +55(71) 3283-8521; Fax: +55(71) 3283-8551 - E-mail: reynam@cpgg.ufba.br
} 


\section{INTRODUCTION}

The difficulty of estimating subsurface model parameters through seismic data is the problem that the full-waveform inversion (FWI) attempts to solve and is rapidly becoming a standard tool for estimating velocity fields with high resolution. The reformulation of the principle of reverse time migration as a velocity model construction by Tarantola (1984) and Lailly (1983) made possible the implementation of FWI. The FWI procedure needs to solve two problems: the forward modeling, which is the numerical solution of wave propagation and the inverse problem. In addition, in the inversion process there is an objective function that measures the comparison between observed and calculated data obtained for the estimated model, which is minimized.

Depending on the frequency content of the data, the FWI can be highly nonlinear and contain different local minima. Due to this, several authors formulated different alternative methods to mitigate the problem, starting with the multiscale approach in the gradient domain (Mora, 1989), then with the heuristic interpretation of the multiscale approach proposed by Bunks et al. (1995), to the current work of Wang et al. (2016) based on wavefield decomposition.

In this work, we propose a variant of the gradient method, based on the work of Kaelin et al. (2007) aiming at a better light compensation. First we calculate the squares of the wavefields of the source and receiver, obtain their respective gradients, and then sum. Thus, it is possible to obtain a more illuminated gradient vector with the better highlighted events, making the search of the global minimum of the objective function more effective.

\section{FWI THEORY}

The application of the multiscale scheme is crucial for the FWI method specially because it can prevent the inversion method from converging to a local minimum. Here, in our case, we have used during the inversion procedure higher frequency data allowing us to obtain inverted models with higher resolution.

The full-waveform inversion method consists of iteratively improving an initial velocity model $(m)$. This optimization is based on the modeling of seismic waves through the solution of the direct problem, which offers the possibility to compute simultaneously the amplitude and the traveltimes of the waves. The solution of the inverse problem involves minimizing the objective function in the space of the model parameters to measure the difference between the predicted $\left(d_{c a l}\right)$ and observed data $\left(d_{o b s}\right)$ (Virieux \& Operto, 2009). The inversion of the directly observed data is computationally impractical. Thus, FWI is formulated as a least squares type optimization problem, in which the objective function of norm $l_{2}$ representing the problem can be defined by (Tarantola, 1984):

$$
\begin{aligned}
F(m) & =\frac{1}{2}\left\|d(m)_{c a l}-d_{o b s}\right\|_{2}^{2} \\
& =\frac{1}{2} \sum_{n s} \int_{0}^{T}\left(d_{c a l}-d_{o b s}\right)^{2} d t,
\end{aligned}
$$

where $F$ is a measure of error, $T$ is the maximum record time. The summation is done in the shot domain, where $n s$ is the total number of shots. The purpose of this formulation is to find the model $m$ so that the functional $F(m)$ is minimum.

This minimization is done in a recurrent way, that is, given a current model $m_{k}$, we search for a next model $m_{k+1}$, which theoretically should be closer to the true model.

The iterative process can be deduced using the second order Taylor-Lagrange approximation (Virieux \& Operto, 2009) and the updating of the model is given by:

$$
m_{k+1}=m_{k}-\alpha_{k} H_{k}^{-1} \nabla F_{k} .
$$

where $H_{k}$ is Hessian matrix, which correspond to the second derivatives of the objective function and the curvature of $F$ in $m_{k} . \alpha_{k}$ is step length which represents the magnitude of the update vector. In the first iteration, $\alpha_{k}$ is computed by Eq. (19) and for the other iterations was used the method presented by Barzilai \& Borwein (1988) adapted by Zhou et al. (2006), $\nabla F_{k}$ is the gradient of the misfit function, i.e., $\frac{\partial F}{\partial m}$.

\section{Rapid Expansion Method}

The efficient solution of the direct problem has great relevance in the FWI, since the difference between the observed and estimated data must only contain information about the model. That is, the modeling procedure can not produce events that do not exist in the observed data. This procedure is performed with the extrapolation of the wavefield on a physical medium through a forward modeling operator. This operator should be implemented to include the elastic modulus and density Virieux \& Operto (2009), however, this implementation is still computationally difficult. Thus, propagation of the wave can be understood by considering a purely acoustic medium in which no transverse waves are propagated.

We consider the following acoustic wave equation, which predicts only the propagation of Iongitudinal waves:

$$
\frac{\partial^{2} u(\mathbf{x}, t)}{\partial t^{2}}+L^{2} u(\mathbf{x}, t)=f(\mathbf{x}, t)
$$

where $-L^{2}=c^{2}(\mathbf{x}) \nabla^{2}, c(\mathbf{x})$ is the velocity of propagation, $\mathbf{x}=(x, y, z)$ is the position vector, $\nabla^{2}=$ 
$\left(\frac{\partial^{2}}{\partial x^{2}}+\frac{\partial^{2}}{\partial y^{2}}+\frac{\partial^{2}}{\partial z^{2}}\right)$ is the Laplacian operator in cartesian coordinates and $f(\mathbf{x}, t)$ is the source term.

The approach that we use to solve Eq. (3) is called variations of parameters (VOP). Thus, the general solution of $u(\mathbf{x}, t)$ to Eq. (1) on $[0, t]$ is written as:

$$
\begin{aligned}
u(\mathbf{x}, t)= & u_{0} \cos (L t)+\frac{\dot{u}_{0}}{L} \sin (L t) \\
& +\frac{1}{L} \int_{0}^{t} f(\mathbf{x}, s) \sin [L(t-s)] d s
\end{aligned}
$$

where $u(\mathbf{x}, t=0)=u_{0}$ and $\left.\frac{\partial u(\mathbf{x}, t)}{\partial t}\right|_{t=0}=u_{0}$.

Equation (4) is the fundamental equation from which we derive the integration procedure. Now, if Eq. (4) is reevaluated using the intervals $[t, t+\Delta t],[t, t-\Delta t]$ and by adding them and evaluating the resulting integral, we obtain the following complete solution of 3 , which includes the source term and is given by:

$$
\begin{gathered}
u(\mathbf{x}, t+\Delta t)+u(\mathbf{x}, t-\Delta t)= \\
2 \cos (L \Delta t) u(\mathbf{x}, t)+S(\mathbf{x}, t \pm \Delta t)
\end{gathered}
$$

where,

$$
S(\mathbf{x}, t \pm \Delta t)=\frac{\Delta t^{2}}{2}[f(\mathbf{x}, t+\Delta t)+f(\mathbf{x}, t-\Delta t)] .
$$

The rapid expansion method is an efficient way of numerically solving the acoustic wave equation (Pestana \& Stoffa, 2009). This technique can extrapolate the wavefield with higher frequencies and larger sampling intervals in time and space than the usual finite-difference scheme, thus being more stable and less dispersive than the conventional finite-difference scheme.

Following Kosloff et al. (1989) and based on the expansion method presented by Tal-Ezer et al. (1987) the cosine function can be expanded as

$$
\cos (L \Delta t)=\sum_{k=0}^{\infty} C_{2 k} J_{2 k}(\Delta t R) Q_{2 k}\left(\frac{i L}{R}\right),
$$

where $C_{2 k}=1$ for $k=0$ and $C_{2 k}=2$ for $k>0, J_{2 k}$ represents the Bessel function of order $2 k$ and $Q_{2 k}(w)$ are the modified Chebyshev polynomials. The term $R$ is a scalar larger than the range of eigenvalues of $-L^{2}$ and it is the same $R$ which appeared in the original Tal-Ezer method (Tal-Ezer et al., 1987).

Since (7) contains only even polynomials, it is more convenient to use the relation,

$$
Q_{k+2}(w)=2\left(1+2 w^{2}\right) Q_{k}(w)-Q_{k-2}(w) .
$$

The recursion is initiated by

$$
Q_{0}(w)=1 \quad \text { and } \quad Q_{2}(w)=1+2 w^{2},
$$

where we have replaced $i L / R$ by $w$.

For $2 \mathrm{D}$ wave propagation, and considering the constant velocity case, $R$ is given by $R=\pi c \sqrt{\left(1 / \Delta x^{2}\right)+\left(1 / \Delta z^{2}\right)}$. In general $c$ should be replaced by $c_{\max }$, the highest velocity in the grid, and $\Delta x, \Delta y$ and $\Delta z$ are the spatial grid spacing (Tal-Ezer et al., 1987).

The sum in (7) is known to converge exponentially for $k>$ $\Delta t R$ and the summation can be safely truncated with a $k$ value slightly greater than $\Delta t R$.

In this way, the stability of the REM is ensured, since the number of terms used in the expansion is directly proportional to the used time sampling interval. Thus, any $\Delta t$ can be used, provided that the number of terms calculated will be sufficient to guarantee the convergence and the stability of the method. Therefore, the use of REM makes the wave propagation FWI more stable and free of numerical dispersion when high frequency components are inserted in the modeling scheme (dos Santos \& Pestana, 2015).

\section{Computation of the gradient}

The gradient of the objective function $\nabla F(m)$ measures the discrepancy of the difference between estimated and observed data, with respect to each of the model parameters. The gradient can be calculated numerically by perturbing each of the model parameters individually, noting this variation in the objective function. However, generally the models used in FWI can have a very large number of parameters, which makes the derivation for each parameter of the model computationally unfeasible.

A good alternative to perform the gradient computation is to make use of the adjoint method. This method can calculate the objective function gradient without requiring the explicit numerical calculation of the partial derivatives of $F(m)$ relative to the parameters of the model (Plessix, 2006). The gradient can be then calculated in time domain (Bunks et al., 1995) using the following formulation:

$$
\nabla F(x)=\frac{2}{c^{3}} \sum_{n s} \sum_{t=0}^{t_{\max }} \ddot{u}_{s}(x, t) u_{r}(x, t),
$$

where $n s$ is the total number of shots. $\ddot{u}_{s}$ corresponds to the second time derivative and can be obtained from:

$$
\ddot{u}_{s}(x, t) \approx \frac{\partial^{2} u}{\partial t^{2}}=\frac{u^{n+1}-2 u^{n}+u^{n-1}}{\Delta t^{2}},
$$

where, $u^{n+1}, u^{n}$ and $u^{n-1}$ are the future, present and past wavefields, respectively. 
By using the following relation

$$
u^{n+1}+u^{n-1}=2 \cos (L \Delta t) u^{n},
$$

where $\cos (L \Delta t)$ is given by Eq. (7) and the Eq. (11) can be expressed as:

$$
\ddot{u}_{s}=\frac{2\left[\sum_{k=0}^{\infty} C_{2 k} J_{2 k}(\Delta t R) Q_{2 k}\left(\frac{i L}{R}\right)-1\right]}{\Delta t^{2}} u^{n}
$$

Additionally, we need to compute $u_{r}$ which is the field resulting from the reverse propagation of the residue $\left(d_{c a l c}-d_{o b s}\right)$ in the current velocity model. The residue wavefield, $u_{r}$, is called the adjoint state variable and can be computed by the following equation:

$$
\frac{1}{c(x)^{2}} \frac{\partial^{2} u_{r}(x, t)}{\partial t^{2}}=\nabla^{2} u_{r}(x, t)+\left(d_{c a l c}-d_{o b s}\right) .
$$

The source term, which is propagated to generate these wavefields, depends on the formulation of the objective function that is minimized in the FWI procedure. That is, the adjoint source is the derivative of the objective function with respect to the modeled wavefield $\left(\frac{\partial F(m)}{\partial u}\right)$.

\section{Preconditioning method using source-receiver illumination - PSRI method}

In order to improve the computation of the gradient and suppress the noises, Kaelin et al. (2007) proposed to divide Eq. (10) by the illumination of the source and the receivers, which can be expressed as:

$$
\nabla F_{s}(x)=\frac{2}{c^{3}} \frac{\sum_{n s} \sum_{t=0}^{t_{\max }} \ddot{u}_{s}(x, t) u_{r}(x, t)}{\sum_{n s} \sum_{t} \ddot{u}_{s}^{2}(x, t)},
$$

and

$$
\nabla F_{r}(x)=\frac{2}{c^{3}} \frac{\sum_{n s} \sum_{t=0}^{t_{\max }} \ddot{u}_{s}(x, t) u_{r}(x, t)}{\sum_{n s} \sum_{t} u_{r}^{2}(x, t)},
$$

Eq. (15) is intended to highlight the shallower reflectors and (16) tries to highlight the deepest reflectors.

Thus, by combining the two previous imaging conditions (15) and (16), we can obtain equal illumination for all reflectors, and the gradient is defined as:

$$
\nabla F_{s r}(x)=\nabla F_{s}(x)+\nabla F_{r}(x) .
$$

In the FWI procedure, Eq. (17) proved to be very efficient, improving the amplitude values of the conventional gradient (Eq. 10) and consequently increasing the resolution of the inverted velocity models.

\section{Convergence condition of the inversion}

In this work, the condition used to reduce the objective function and assure the convergence (Nocedal \& Wright, 2006) of the process has to satisfy:

$$
F\left(m_{k}+\alpha_{k} p_{k}\right)<F\left(m_{k}\right)
$$

In this way, the length of the step is evaluated using this condition, which ensures the decrease of the data mismatch at each iteration.

If the length of the step is accepted, in other words, satisfying Eq. (18), the modeling performed to evaluate this condition is used in the next iteration of FWI, avoiding extra computational cost (dos Santos \& Pestana, 2015). If the size of the step is rejected, a new $\alpha_{k}$ is computed using a backtracking method described in Algorithm 1 (Nocedal \& Wright, 2006), until the condition is satisfied.

\section{Determining the step length of the first iteration}

Another challenge that must be solved is the determination of the step length of the first iteration, which is where the backtracking method begins. In linearized inversion problems the step length can be estimated by the steepest-descent method. In this work, the initial step length was implemented based on the work of Pica et al. (1990) from a small perturbation in the velocity model ensuring that the value of the subsequent objective function is less than the previous value. The parameter vector of the model is disturbed using a differential step length $\epsilon$, which corresponds to the solution of:

$$
\max \left(\epsilon\left|p_{k}\right|\right) \leq \frac{\max \left(\left|m_{k}\right|\right)}{100 \sigma_{k}}
$$

where $\sigma_{k}$ is a scalar between 0 and 1 , which determines the maximum percentage in which the value of each model parameter will change.

\section{FWI EXAMPLES}

\section{Marmousi velocity model}

The Marmousi model contains a series of normal faults and resulting tilted blocks complicates the model towards its center. The model sits under approximately $32 \mathrm{~m}$ of water and is $9.2 \mathrm{~km}$ in length and $3 \mathrm{~km}$ in depth. The numerical grid consists of 375 $\times 369$ grid nodes in total. The spatial sampling in the velocity grid is $25 \mathrm{~m}$ in the horizontal direction and $8 \mathrm{~m}$ in the vertical direction. The inversion parameters consist of 62 shots, spacing between shots of $150 \mathrm{~m}, 369$ receivers, peak frequency of $15 \mathrm{~Hz}$, recording time of $3 \mathrm{~s}$ and 751 samples in time. 
Algorithm 1-Backtracking method

1: $\alpha_{k} \leftarrow$ alpha $^{0}$

2: compute $F\left(m_{k}+\alpha_{k} p_{k}\right)$;

3: while $F\left(m_{k}+\alpha_{k} p_{k}\right)>F\left(m_{k}\right)$ do

4: $\tau \leftarrow r[0,1]$;

5: $\alpha_{k} \leftarrow \tau \alpha_{k}$;

6: compute $F\left(m_{k}+\alpha_{k} p_{k}\right)$;

\section{7: end while}

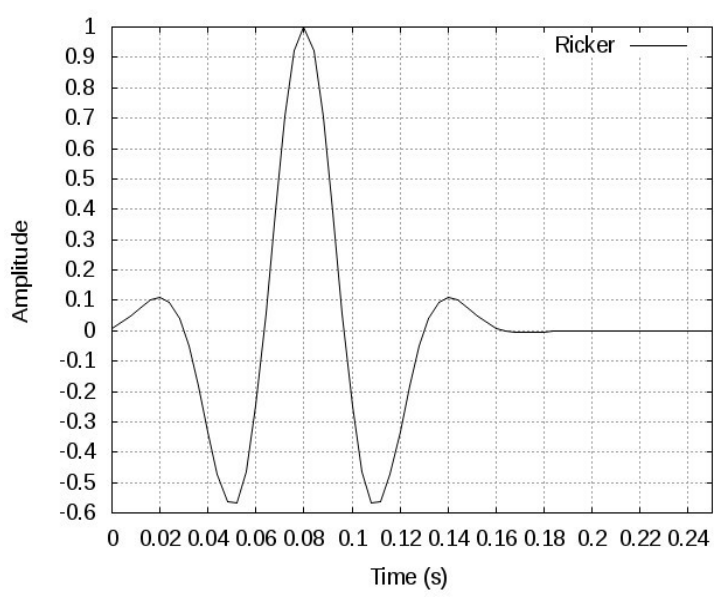

(a)

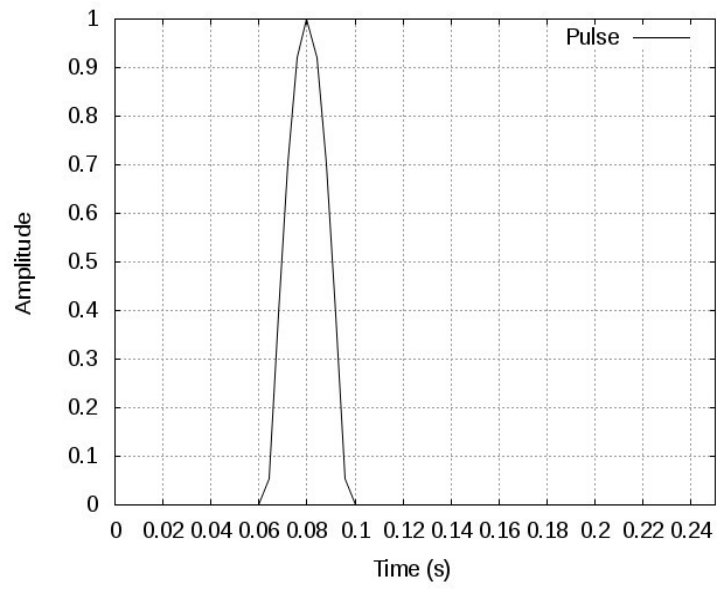

(b)

Figure 1 - Source signatures used in the inversion procedure: (a) Ricker; (b) Pulse.

The FWI procedure was performed for two types of source signature (Fig. 1). The first is a Ricker wavelet, a well-known source in the geophysical literature. The second source is a pulse. The difference between them is that the Ricker represents a function that has more than one critical point, whereas, the pulse has only one critical point of maximum. This difference in the number of critical points may interfere with the seismic data phase. Thus, we evaluated the performance of FWI for both source types and concluded that the inversion using the pulse as source provided velocity fields with higher resolution than the inversion using the Ricker source.

In addition, for each type of source, two methods for the calculation of the gradient vector were implemented: the conventional gradient method and the gradient preconditioning method using source-receiver illumination compensation (PSRI) applied in the image condition of the gradient. In the tests performed, a better efficiency of the PSRI method was noted compared to the conventional gradient method. The best performance of the PSRI method occurs for both source types, that is because the source-receiver illumination compensation is a better approximation of the in- verse of the Hessian matrix than the identity matrix used in the conventional gradient method.

The observed data (Fig. 2) was generated using the REM with the true velocity field of the Marmousi model (Fig. 3). The input velocity field (Fig. 4) which was initiate the inversion is a smoothed version of the original model. The observed data was filtered for each frequency band and the calculated data was modeled with these corresponding frequencies using the updated fields and then compared with the observed data. In this work, 25 iterations by frequency band were computated.

The inversion procedure starts by updating the observed low frequency seismic data filtered in the ranges of $0-2.5 \mathrm{~Hz}$ and 0 $5.0 \mathrm{~Hz}$, which will result in the recover of the large structures of the model as we can notice in Figure 5: (a) and (b), Figure 6: (a) and (b), Figure 8: (a) and (b) and Figure 9: (a) and (b). After a fixed number of iterations, we increased the frequency range, to $0-7.5 \mathrm{~Hz}$ and $0-10.0 \mathrm{~Hz}$ which resulted in the delineation of small structures. The results in Figure 5: (c) and (d), Figure 6: (c) and (d), Figure 8: (c) and (d) and Figure 9: (c) and (d), for these intermediate ranges of frequency, show that the resolution 


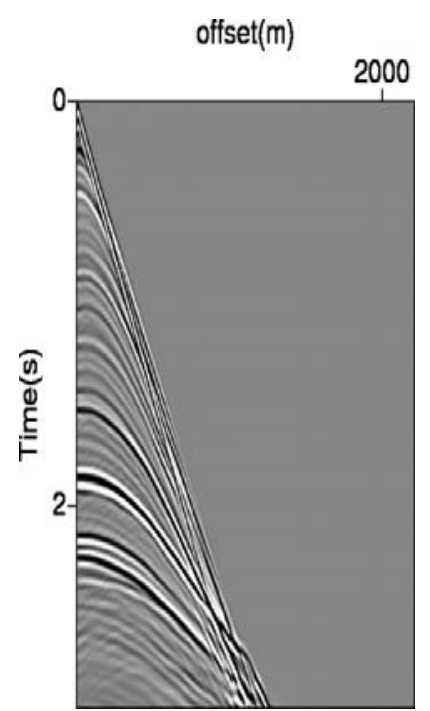

(a)

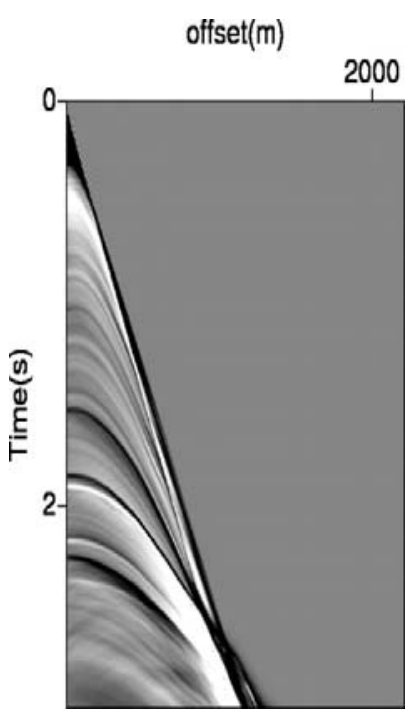

(b)

Figure 2 - Observed data generated using: (a) Ricker source; (b) Pulse source.

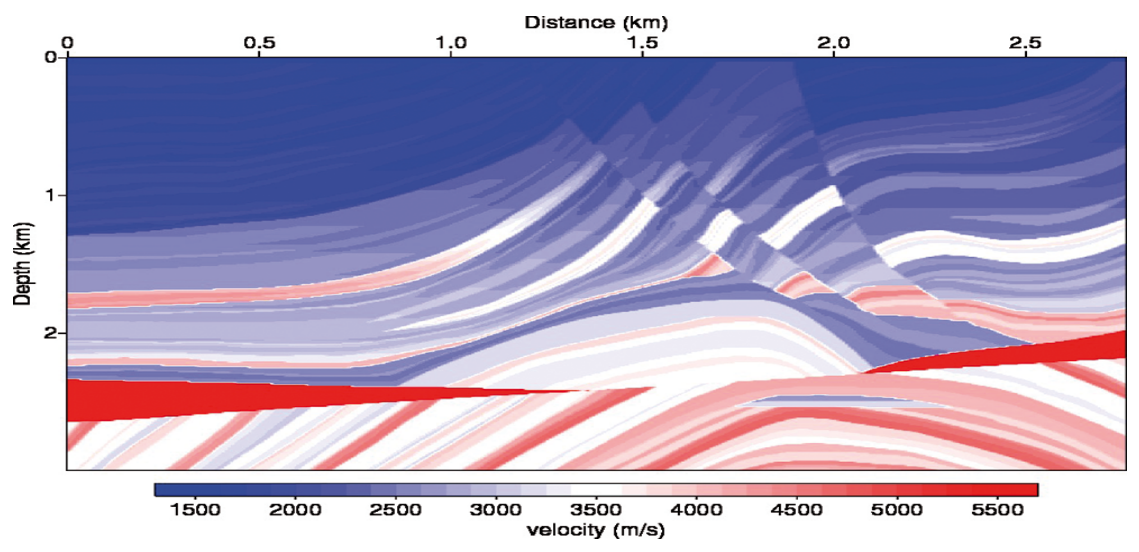

Figure 3 - Marmousi true velocity model.

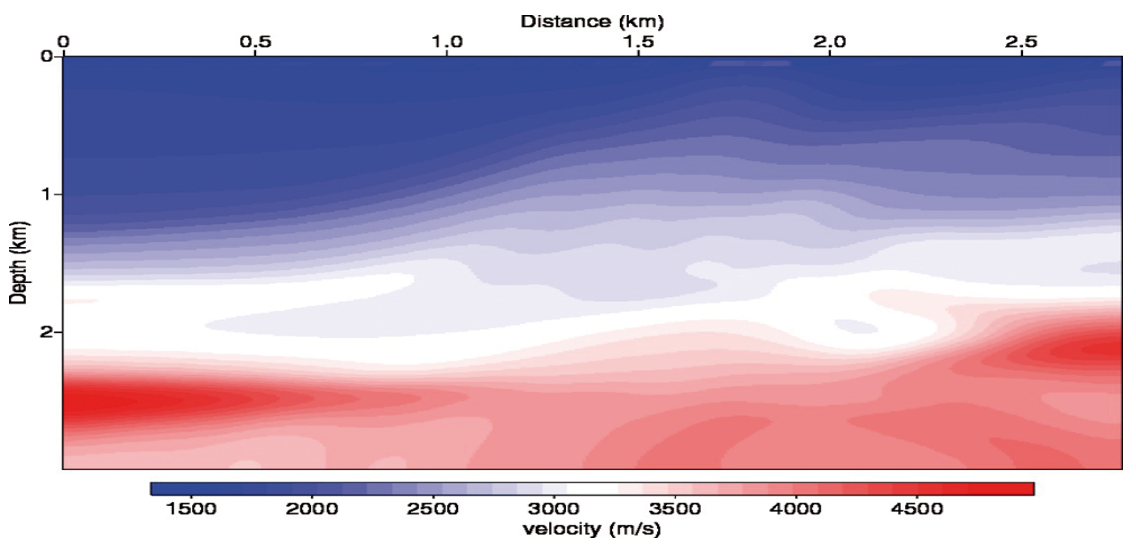

Figure 4 - Marmousi initial velocity model. 


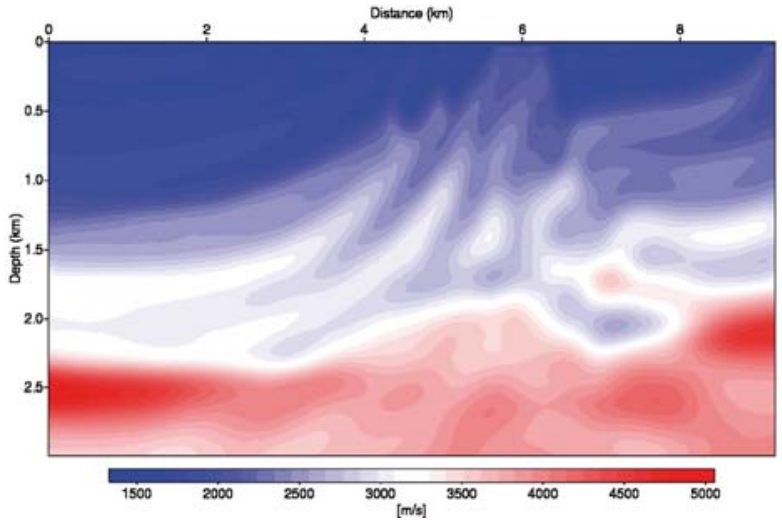

(a)

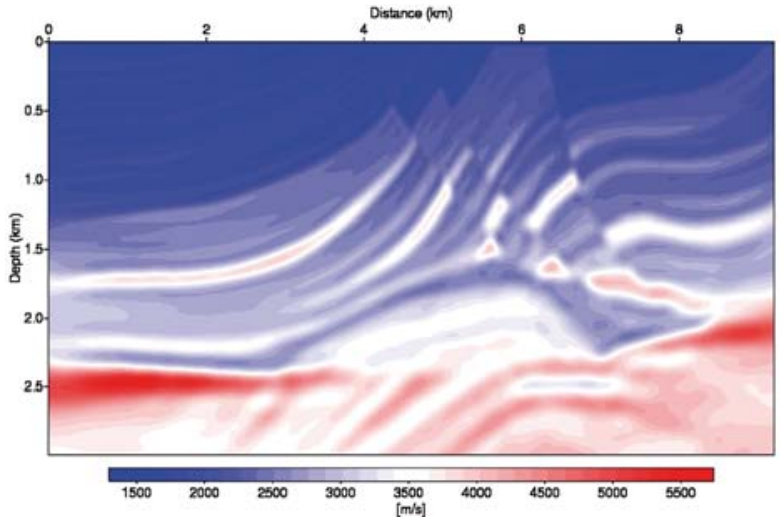

(c)

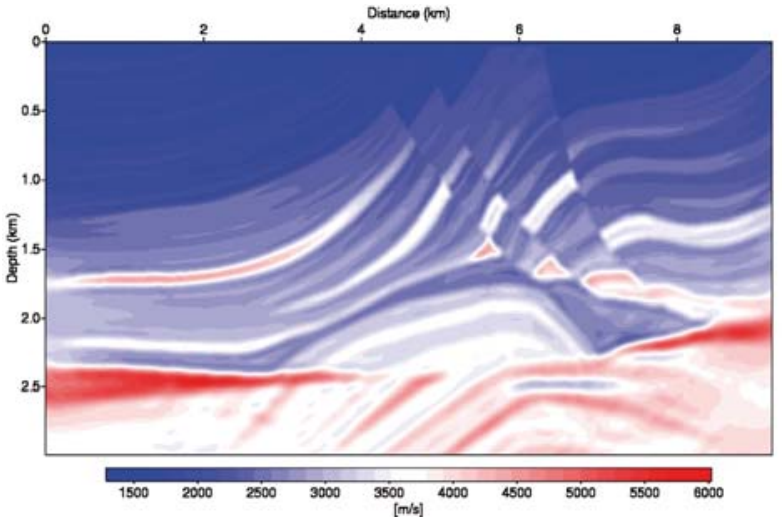

(e)

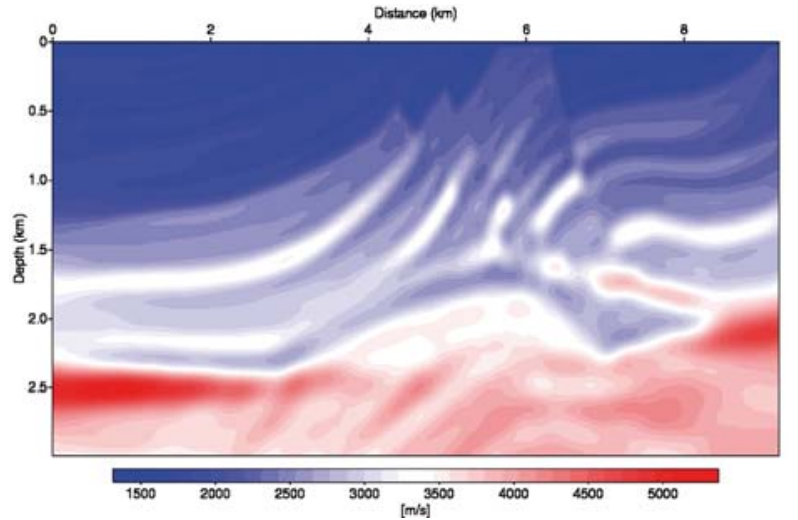

(b)

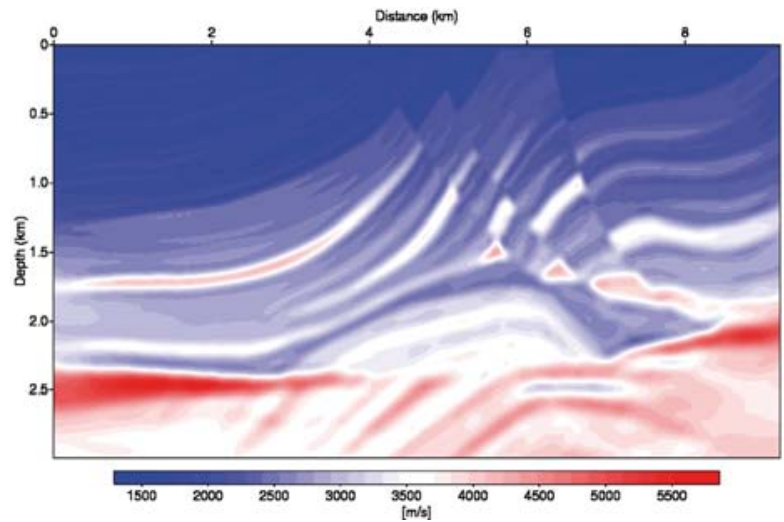

(d)

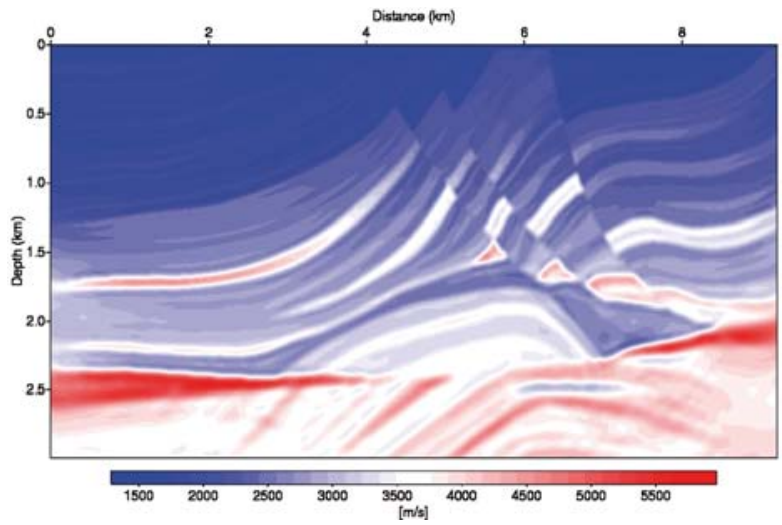

(f)

Figure 5 - Estimated model using Ricker source for the gradient method for peak frequency of: (a) $2.5 \mathrm{~Hz}$; (b) $5 \mathrm{~Hz}$; (c) $7.5 \mathrm{~Hz}$; (d) $10 \mathrm{~Hz}$; (e) $12.5 \mathrm{~Hz}$; (f) $15 \mathrm{~Hz}$.

has increased and the inverted model is comparable to the true one present in Figure 4. Finally the process ends with the inversion of the high frequency seismic data, which inserts higher resolution details on the inverted final model (Fig. 5: (e) and (f), Fig. 6: (e) and (f), Fig. 8: (e) and (f) and Fig. 9: (e) and (f)).

Finally, FWI results using a pulse as source provided velocity models with higher resolution than the inversion using the Ricker wavelet. The PSRI method was also more efficient than the conventional gradient method for both sources used.

The graphs of the objective functions (Figs. 7 and 10), velocity profile (Fig. 11) and comparison of the number of attempts in the backtracking process (Figs. 12 and 13) show the advantages 


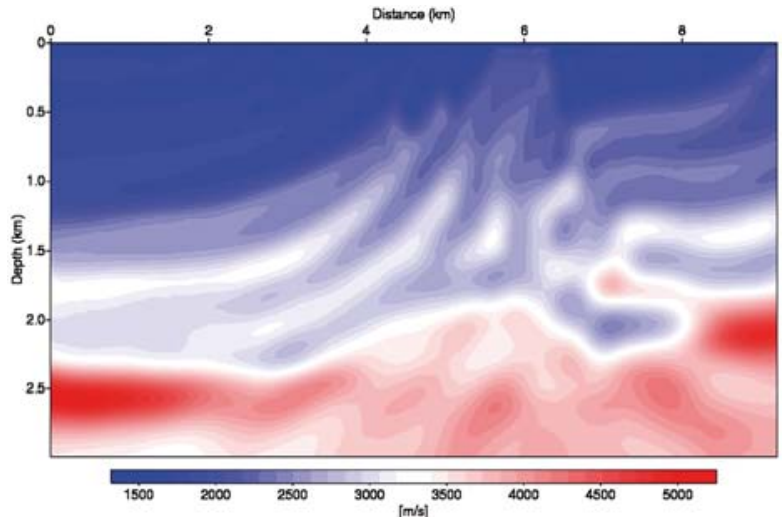

(a)

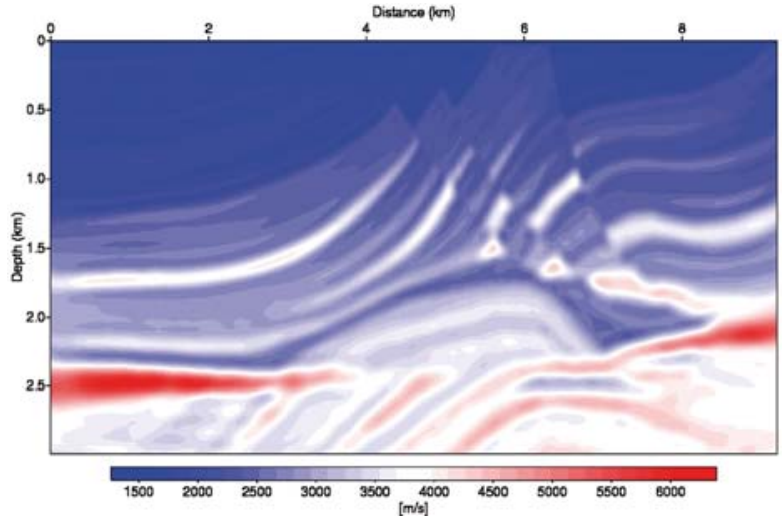

(c)

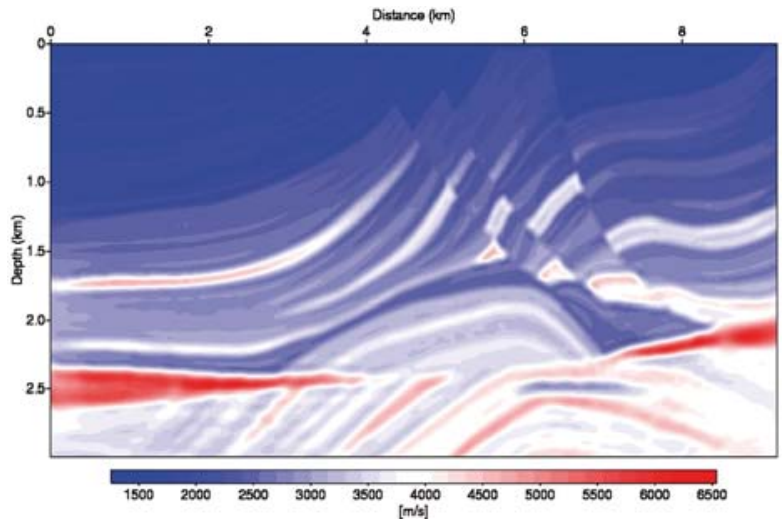

(e)

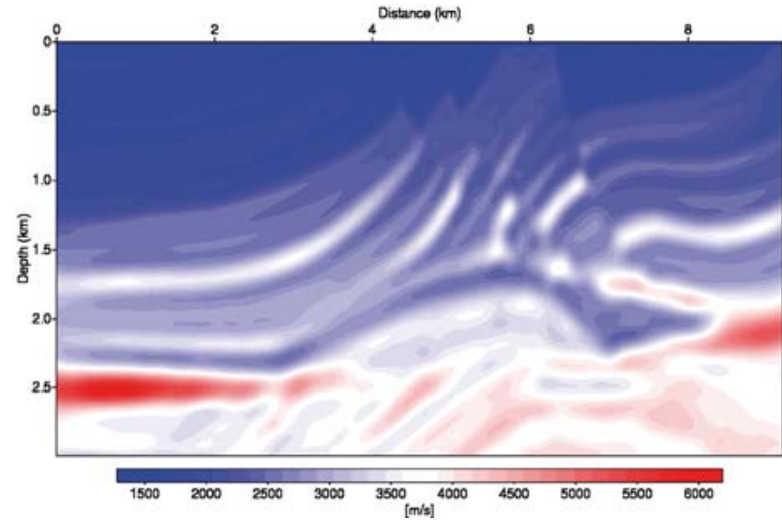

(b)

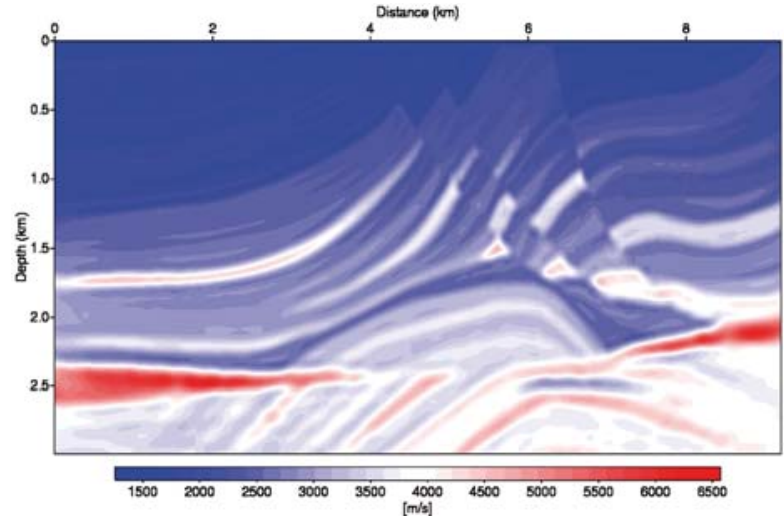

(d)

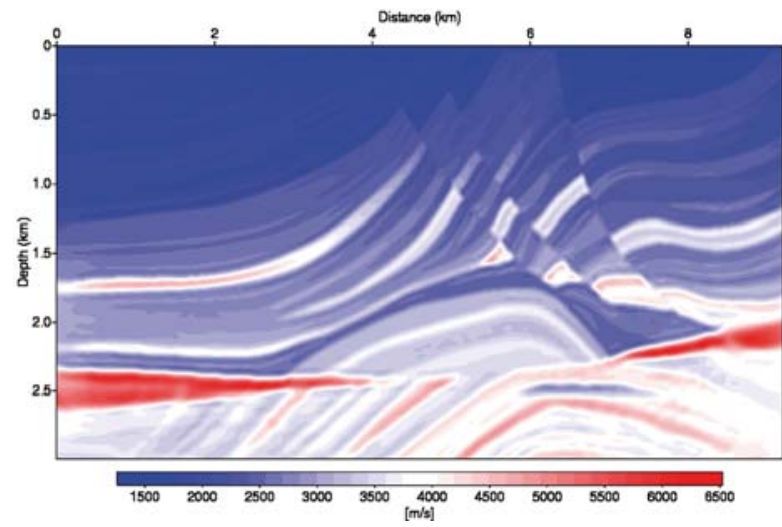

(f)

Figure 6 - Estimated model using Ricker source with the PSRI method for peak frequency of: (a) $2.5 \mathrm{~Hz}$; (b) $5 \mathrm{~Hz}$; (c) $7.5 \mathrm{~Hz}$; (d) $10 \mathrm{~Hz}$; (e) $12.5 \mathrm{~Hz}$; (f) $15 \mathrm{~Hz}$.

and disadvantages of the implemented methods.

\section{CONCLUSION}

Considering the aforementioned results, it was possible verify that FWI with the rapid expansion method and the proposed preconditioning method for the gradient vector led to an overall improve- ment of the procedure and produced velocity models with high resolution. The application of the multiscale approach is crucial to avoid local minimums and obtain models with better resolution.

In the FWI solution, it was evident that the use of a pulse as a source can provide better results than the Ricker source, thus allowing velocity fields with higher resolution, since the pulse has 


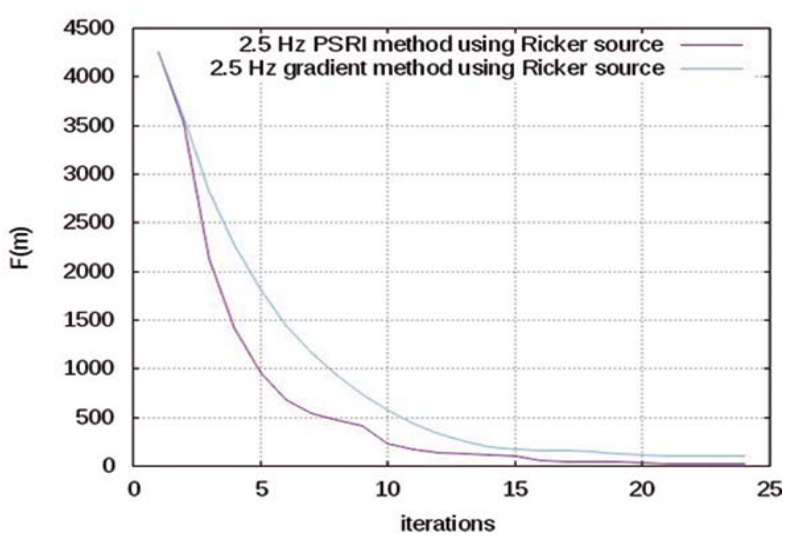

(a)

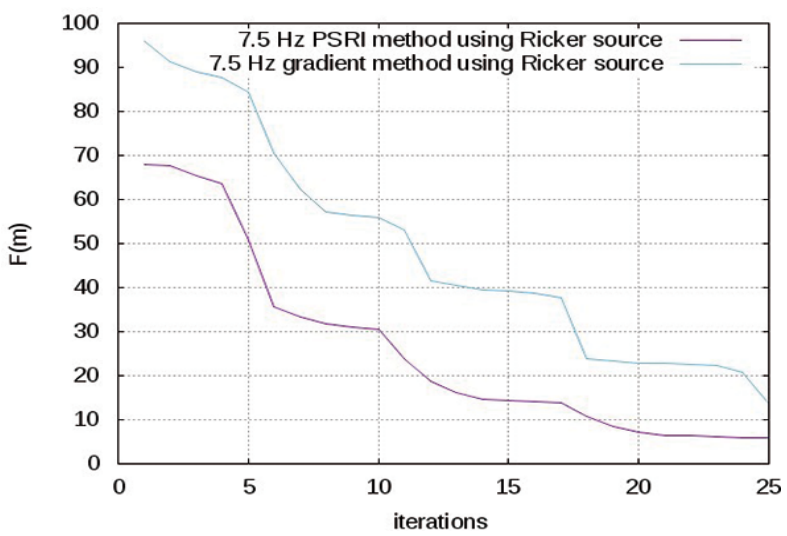

(c)

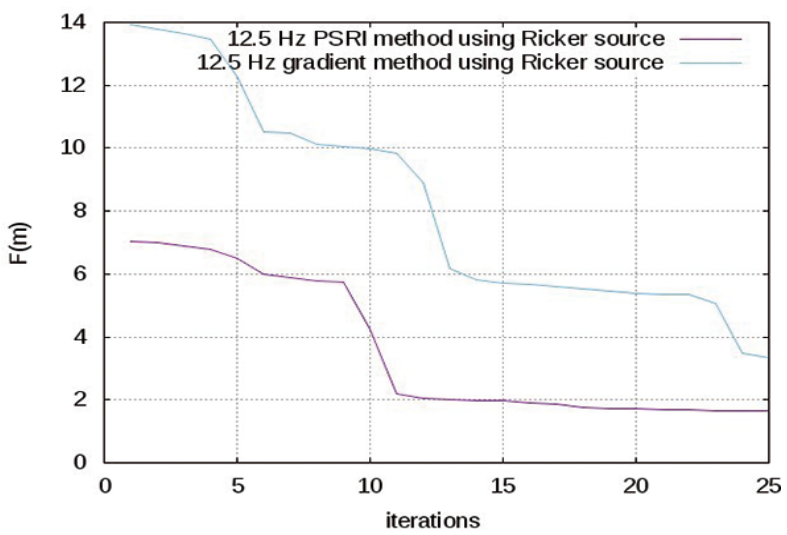

(e)

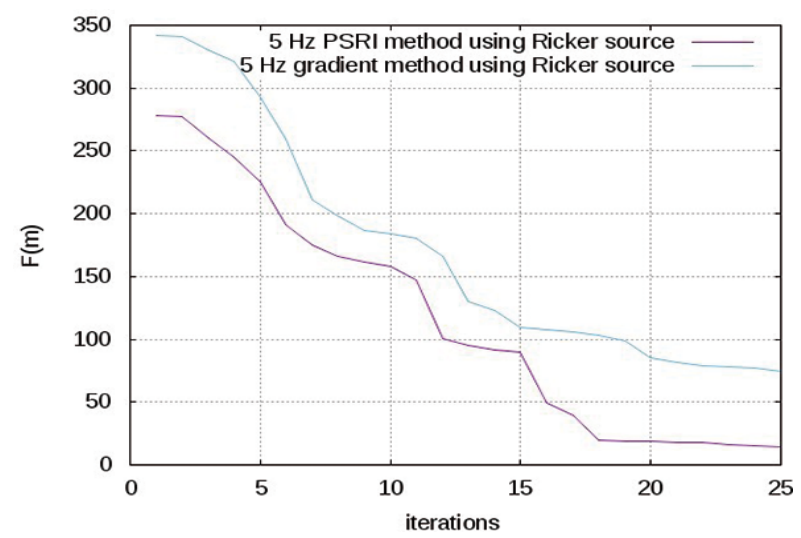

(b)

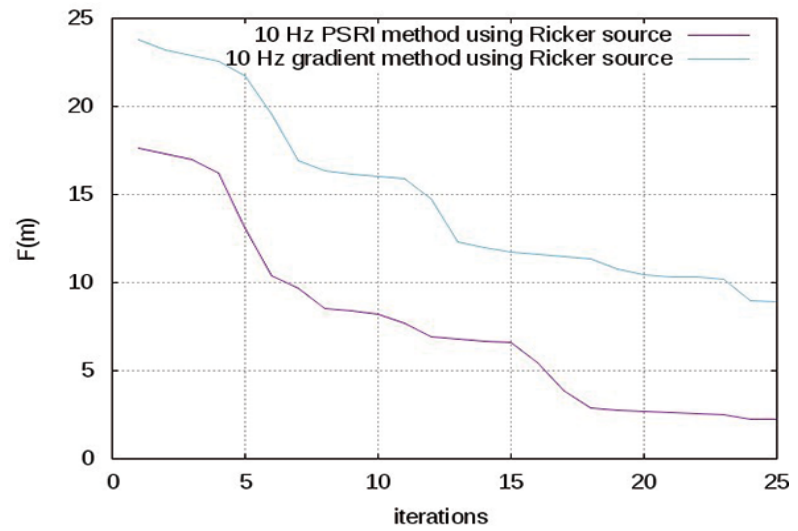

(d)

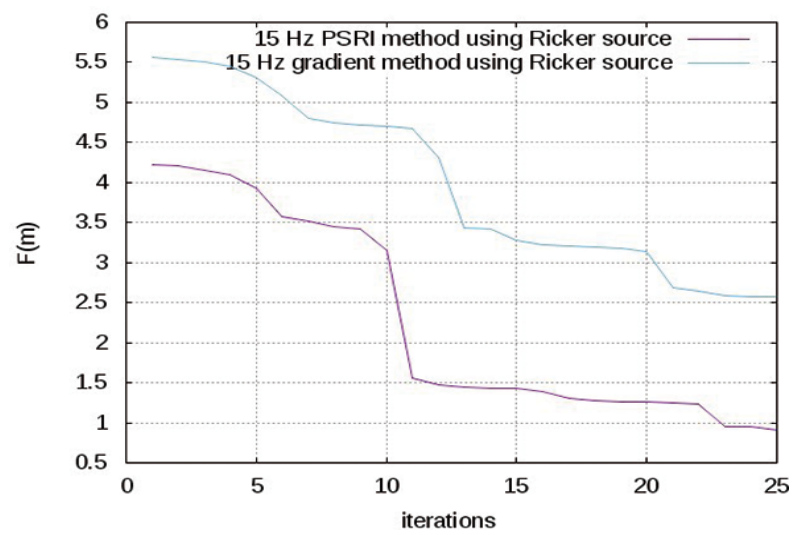

(f)

Figure 7 - Convergence of the objective function using Ricker source for the gradient and PSRI methods with peak frequency of: (a) $2.5 \mathrm{~Hz}$; (b) $5 \mathrm{~Hz}$; (c) $7.5 \mathrm{~Hz}$; (d) $10 \mathrm{~Hz}$; (e) $12.5 \mathrm{~Hz}$; (f) $15 \mathrm{~Hz}$. 


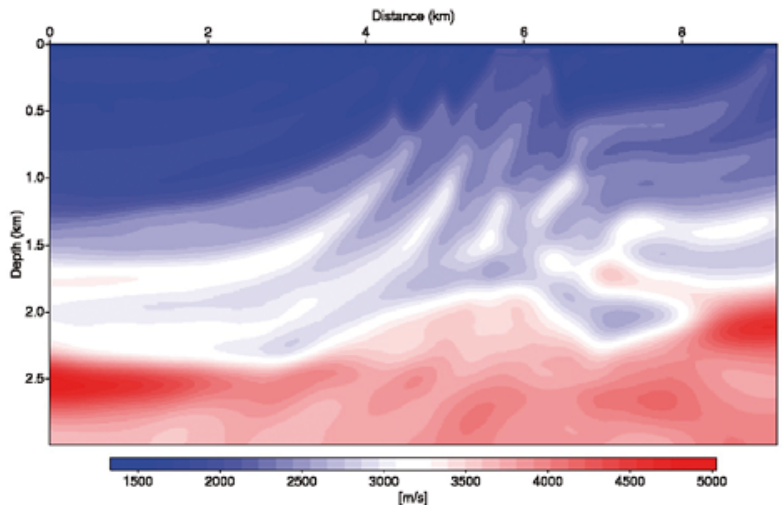

(a)

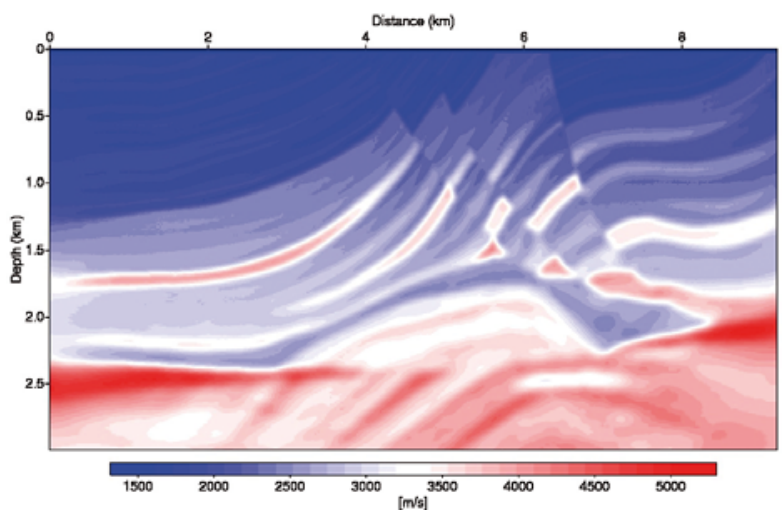

(c)

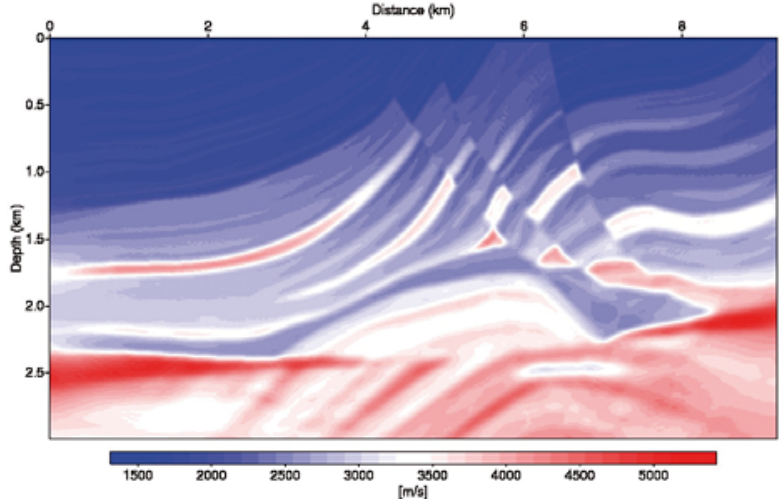

$(e)$

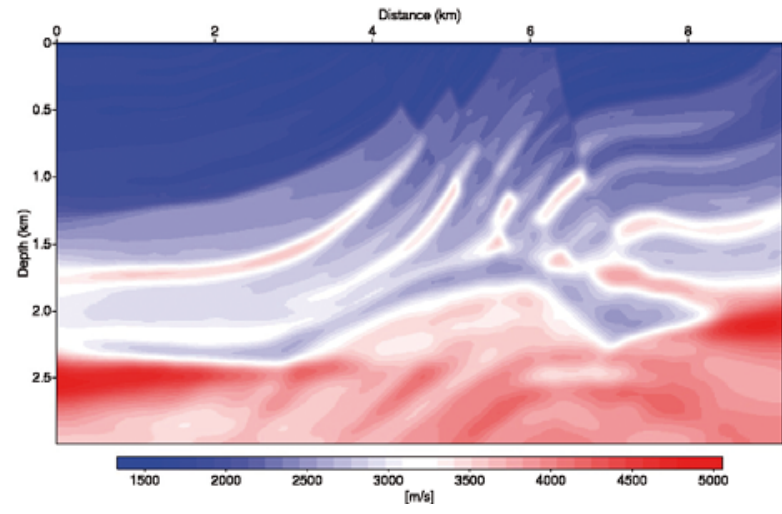

(b)

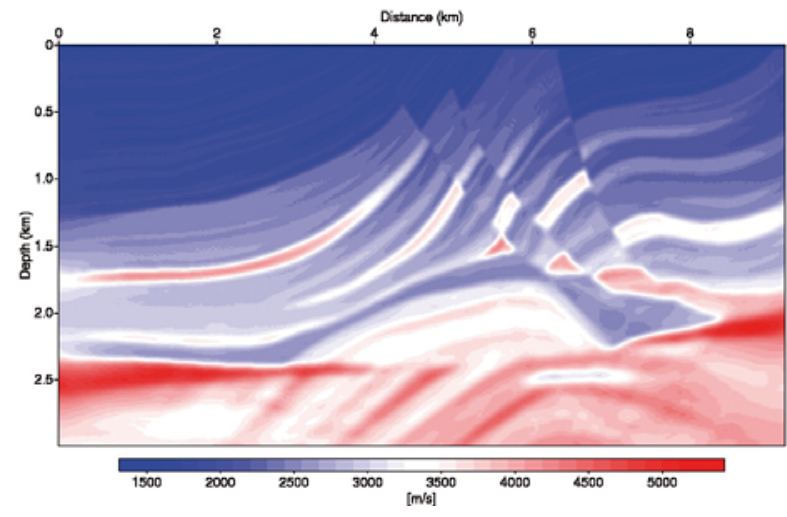

(d)

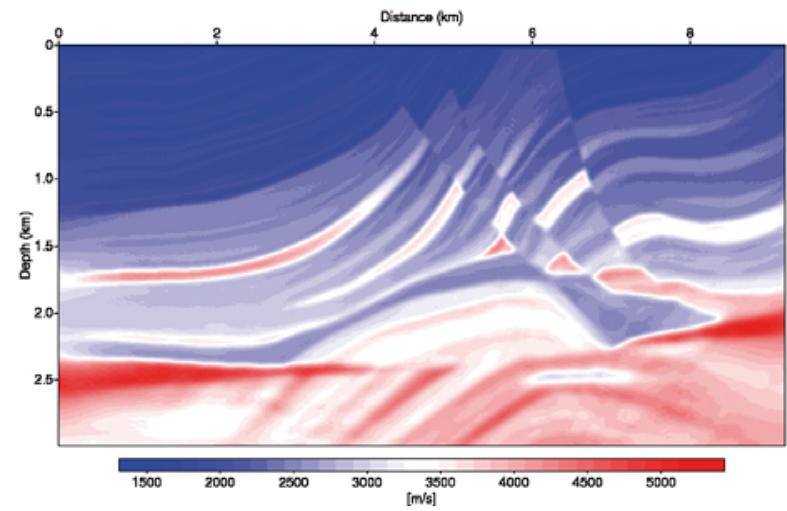

(f)

Figure 8 - Estimated model using pulse source for the gradient method for peak frequency of: (a) $2.5 \mathrm{~Hz}$; (b) $5 \mathrm{~Hz}$; (c) $7.5 \mathrm{~Hz}$; (d) $10 \mathrm{~Hz}$; (e) $12.5 \mathrm{~Hz}$; (f) $15 \mathrm{~Hz}$

no negative amplitudes and its corresponding function only has one critical point of maximum, which may have contributed to avoid problems related to the phase of the seismic data.

The PSRI method used here for computing the gradient vector consists of a light compensation which can be considered an approximation of the inverse of the Hessian matrix. This method proved to be more efficient, converging rapidly for all frequency bands, reducing the objective function faster than the conventional gradient method.

\section{ACKNOWLEDGEMENTS}

This research was supported by Fapesb and INCT-GP/CNPq. The facility support from CPGG/UFBA is also acknowledged. 


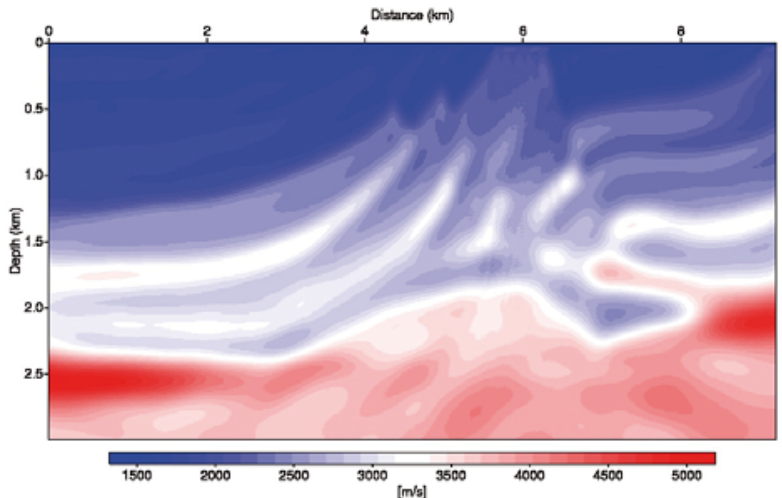

(a)

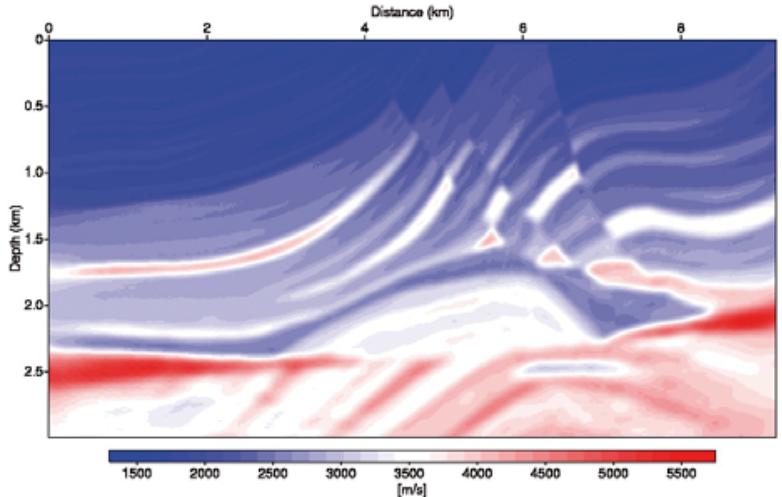

(c)

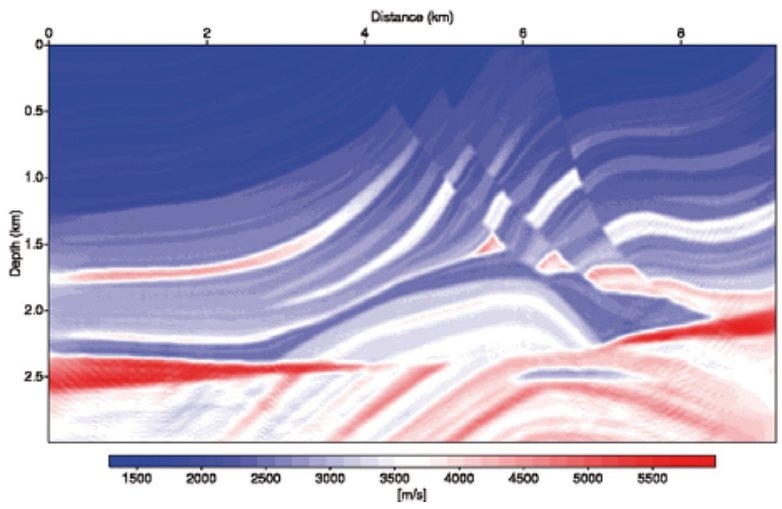

(e)

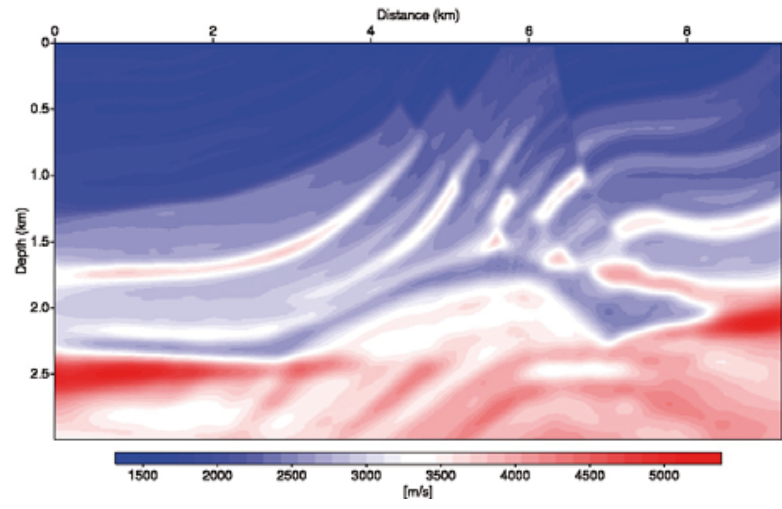

(b)

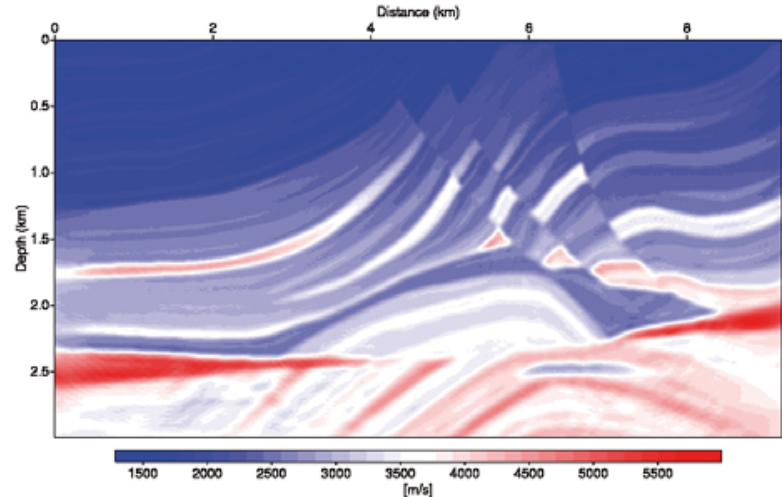

(d)

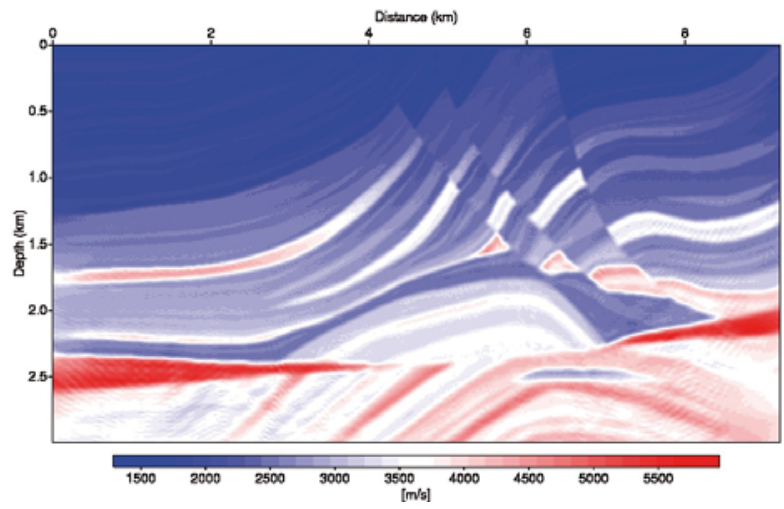

(f)

Figure 9 - Estimated model using pulse source with the PSRI method for peak frequency of: (a) $2.5 \mathrm{~Hz}$; (b) $5 \mathrm{~Hz}$; (c) $7.5 \mathrm{~Hz}$; (d) $10 \mathrm{~Hz}$; (e) $12.5 \mathrm{~Hz}$; (f) $15 \mathrm{~Hz}$.

The authors thank Victor Koehne Ramalho for the help in writing the work.

\section{REFERENCES}

BARZILAI J \& BORWEIN JM. 1988. Two-point step size gradient methods. IMA Journal of Numerical Analysis, 8: 141-148.

BUNKS C, SALECK FM, ZALESKI S \& CHAVENT G. 1995. Multiscale seismic waveform inversion. Geophysics, 60: 1457-1473.

DOS SANTOS AW \& PESTANARC. 2015. Time-domain multiscale fullwaveform inversion using the rapid expansion method and efficient step-length estimation. Geophysics, 80: R203-R216.

KAELIN B, GUITTON A \& ORTIGOSA F. 2007. Illumination effects in rreverese time migration. In: 69th EAGE Conference and Exhibition incorporating SPE EUROPEC 2007. 


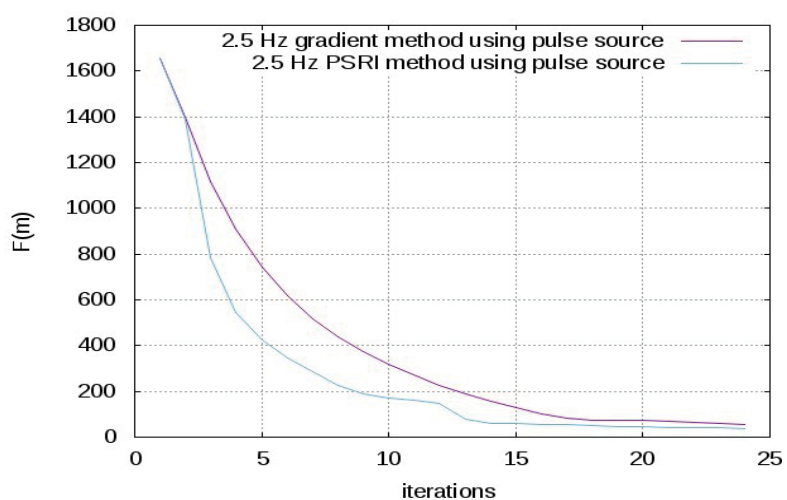

(a)

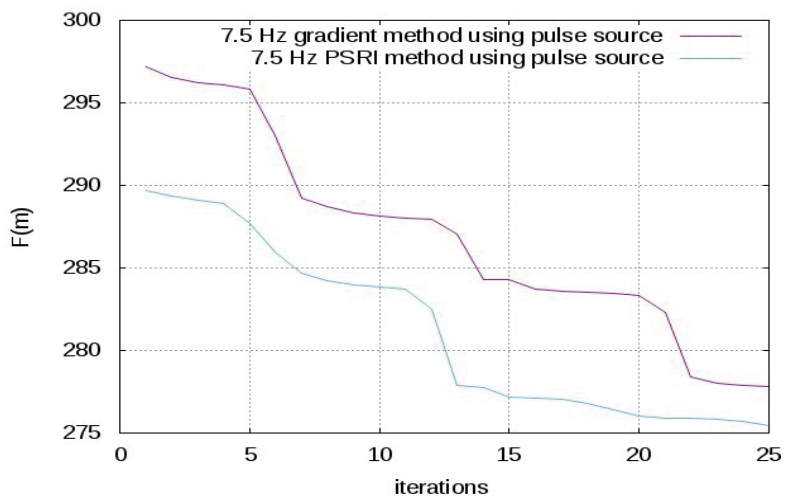

(c)

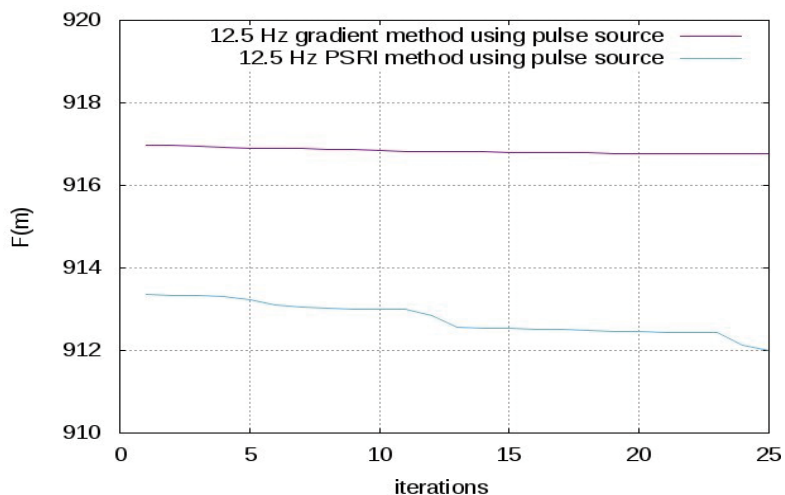

(e)

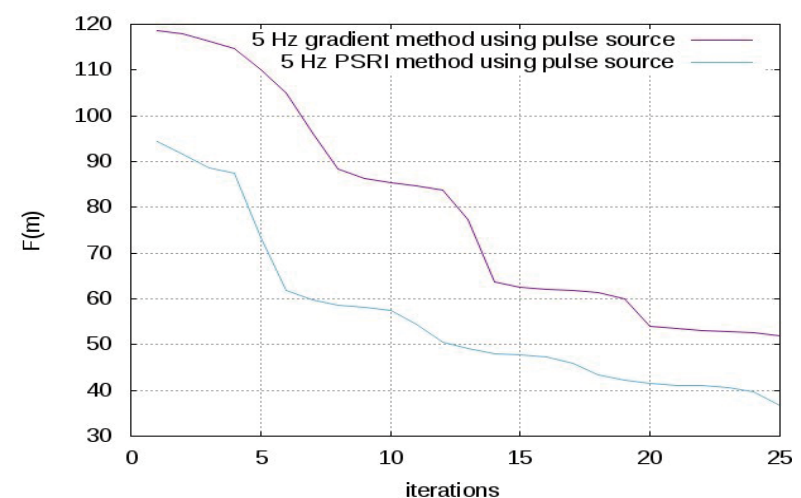

(b)

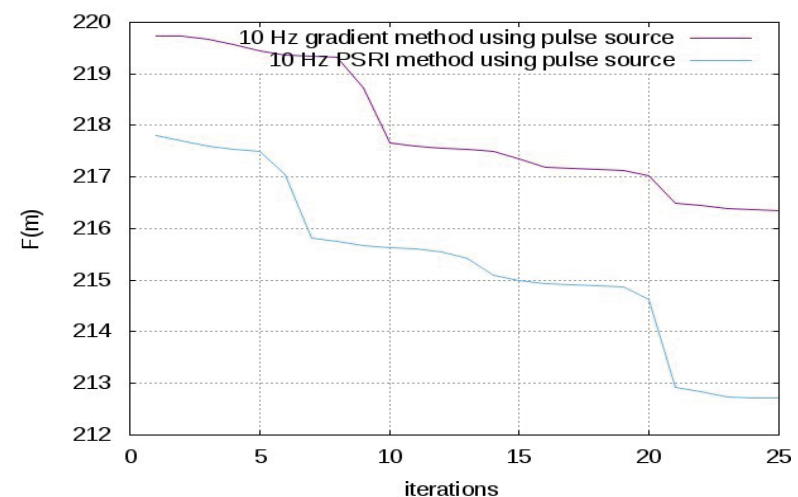

(d)

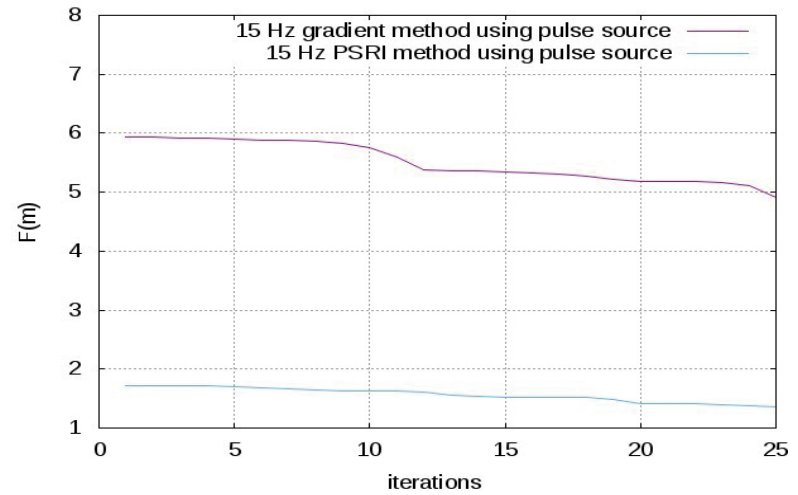

(

Figure 10 - Convergence of the objective function using pulse source for the gradient and PSRI methods with peak frequency of: (a) $2.5 \mathrm{~Hz}$; (b) $5 \mathrm{~Hz}$; (c) $7.5 \mathrm{~Hz}$; (d) $10 \mathrm{~Hz}$; (e) $12.5 \mathrm{~Hz}$; (f) $15 \mathrm{~Hz}$.

KOSLOFF D, FILHO AQ, TESSMER E \& BEHLE A. 1989. Numerical solution of thr acoustic and elastic wave equation by a new rapid expansion method. Geophysical Prospecting, 37: 383-384.

LAILLY P. 1983. The seismic inverse problem as a sequence of before stack migrations.

MORA P. 1989. Inversion = migration + tomography. Geophysics, 54:
$1575-1586$

NOCEDAL J \& WRIGHT S. 2006. Numerical optimization. Springer Science \& Business Media.

PESTANA RC \& STOFFA PL. 2009. Rapid expansion method (REM) for time-stepping in reverse time migration (RTM). Presented at the 2009 SEG Annual Meeting. 


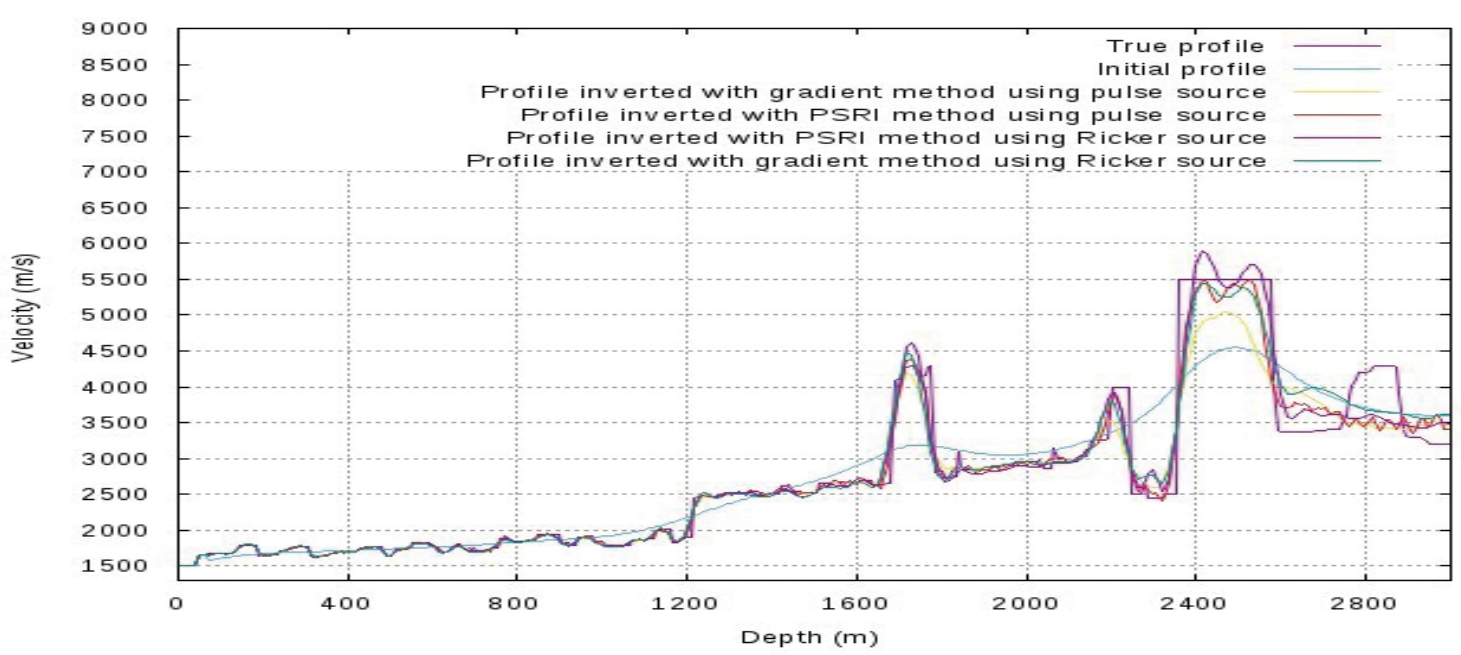

Figure 11 - Comparison between velocity profiles for the different methods.

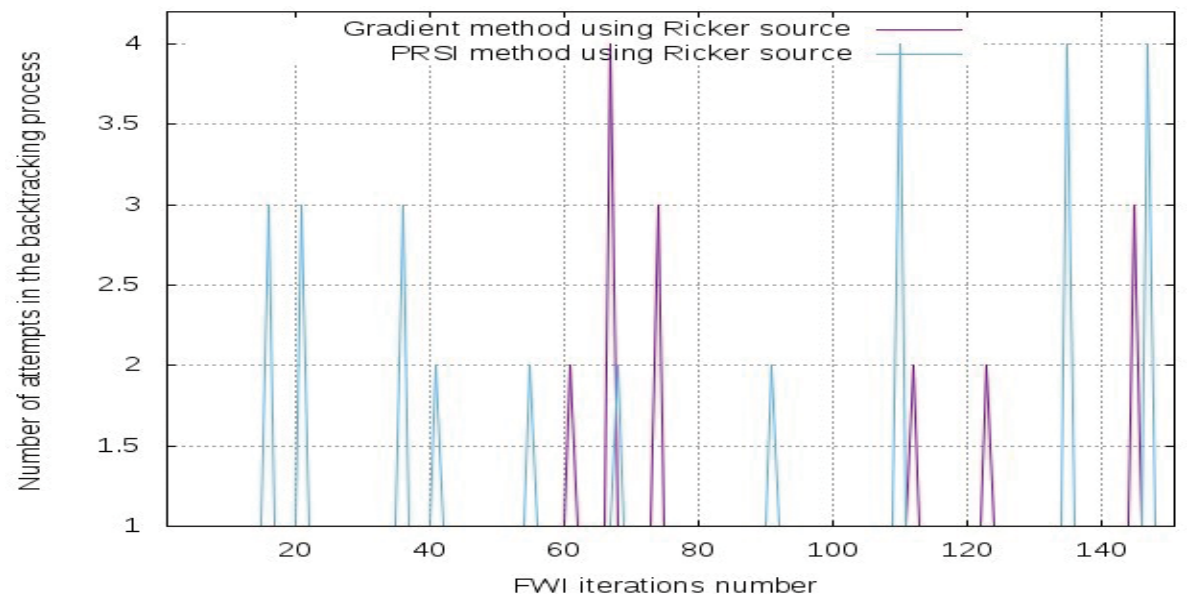

Figure 12 - Comparison of the number of attempts in the backtracking process per FWI iteration using Ricker source.

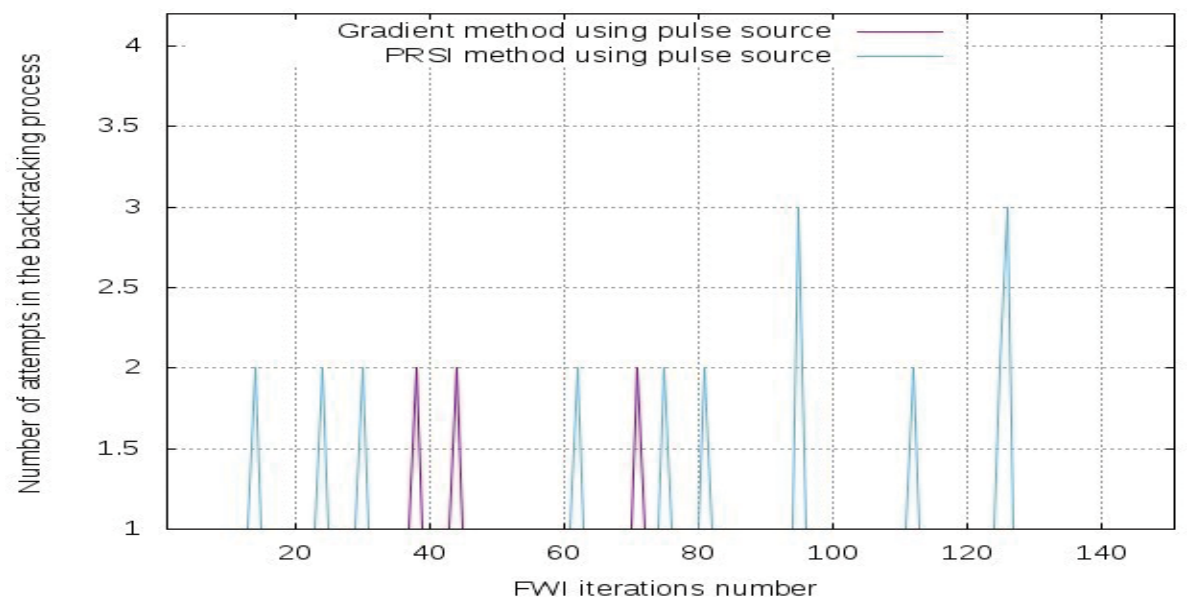

Figure 13 - Comparison of the number of attempts in the backtracking process per FWI iteration using pulse source. 
PICA A, DIET J \& TARANTOLA A. 1990. Nonlinear inversion of seismic reflection data in a laterally invariant medium. Geophysics, 55: 284-292.

PLESSIX R-E. 2006. A review of the adjoint-state method for computing the gradient of a functional with geophysical applications. Geophysical Journal International, 167: 495-503.

TAL-EZER H, KOSLOFF D \& KOREN Z. 1987. An accurate scheme for seismic forward modelling*. Geophysical Prospecting, 35: 479-490.

TARANTOLAA. 1984. Inversion of seismic reflection data in the acoustic approximation. Geophysics, 49: 1259-1266.

VIRIEUX J \& OPERTO S. 2009. An overview of full-waveform inversion in exploration geophysics. Geophysics, 74: WCC1-WCC26.

WANG F, DONNO D, CHAURIS H, CALANDRA H \& AUDEBERT F. 2016. Waveform inversion based on wavefield decomposition. Geophysics, 81: R457-R470.

ZHOU B, GAO L \& DAI Y-H. 2006. Gradient methods with adaptive stepsizes. Computational Optimization and Applications, 35: 69-86.

Recebido em 21 março, 2017 / Aceito em 23 maio, 2017

Received on March 21, 2017 / Accepted on May 23, 2017 